\title{
Sequential intraventricular injection of tigecycline and polymyxin $B$ in the treatment of intracranial Acinetobacter baumannii infection after trauma: a case report and review of the literature
}

\author{
Li Zhong ${ }^{1,2}$, Xue-Zhi Shi ${ }^{3}$, Lei Su ${ }^{3,4}$ and Zhi-Feng Liü ${ }^{3,4^{*}}$ (iD
}

\begin{abstract}
Background: Intracranial infection after craniotomy is one of the most serious postoperative complications, especially multidrug-resistant (MDR) or extensively drug-resistant (XDR) bacterial meningitis, and strongly affects the prognosis of patients. Current treatment experience regarding these infections is scarce.

Case presentation: We report a case of severe intracranial infection of XDR Acinetobacter baumannii (A. baumannii) that was treated by intravenous (IV) injection, sequential intraventricular (IVT) injection of tigecycline and polymyxin $B$, and other anti-infective drugs. Good results were obtained, and the patient was eventually discharged from the hospital. This case is characterized by intracranial infection.
\end{abstract}

Conclusions: The polymyxin B IV + IVT pathway is an ideal treatment strategy for XDR A. baumannii. The tigecycline IVT pathway is also a safe treatment option.

Keywords: Intraventricular injection of tigecycline, Polymyxin B, Intracranial infection, Acinetobacter baumannii

\section{Background}

Intracranial infection after craniotomy is one of the most serious postoperative complications [1]. In two studies, the incidence of bacterial intracranial infections after neurosurgery was 0.3 and $1.5 \%$, respectively $[2,3]$. In the United States, a study conducted between 1998 and 2007 showed that the mortality of postoperative intracranial infection was $14.8 \%$ [4]. Trauma, neurosurgery, cerebrospinal fluid (CSF) leakage, and external devices are all risk factors for bacteria to enter the CSF [3]. The bacteria causing

\footnotetext{
*Correspondence: Zhifengliu7797@163.com

${ }^{3}$ Department of Critical Care Medicine, General Hospital of Southern Theater Command of PLA, Guangzhou 510010, China

${ }^{4}$ Key Laboratory of Hot Zone Trauma Care and Tissue Repair of PLA, General Hospital of Southern Theater Command of PLA, Guangzhou 510010, China Full list of author information is available at the end of the article
}

intracranial infection are mainly gram-negative and grampositive bacteria. In recent years, the proportion of intracranial infections caused by Acinetobacter baumannii (A. baumanni) has been increasing, and the incidence of hospital bacterial meningitis caused by $A$. baumannii accounts for 3.6 to $11.2 \%$ of cases [5]. In another study showing a higher proportion of $A$. baumannii meningitis from January 2004 to December 2015, in 134 patients with bacterial meningitis, gram-negative bacteria accounted for $58.2 \%$, gram-positive bacteria accounted for $41.8 \%$, and the most common microorganisms were $A$. baumannii, accounting for $34.8 \%$; the comparison of mortality data showed that mortality among patients with gram-negative bacteria was greater than that among patients with gram-positive bacteria [6]. A South Korean study showed that A. baumannii 
accounted for $32.5 \%$ of the pathogens studied in 91 patients with bacterial meningitis with an overall mortality of 16.5\% in 91 patients and $26.9 \%$ in those with Acinetobacter infection [7]. Overall, A. baumannii deaths worldwide range from 15.0 to $71.5 \%[8,9]$. In the past several decades, the drug resistance rate of $A$. baumannii has also increased significantly. A microbial monitoring experiment reported that the drug resistance rate of A. baumannii was 30\% [10]. In the face of such high mortality and drug resistance rates, the treatment of intracranial infection caused by $A$. baumannii is urgently necessary. Because the permeability of the blood-brain barrier is poor and bacterial drug resistance increases, the sensitive bacterial inhibition concentration (MIC) increases significantly, and different antibiotics have different abilities to enter the CSF, limiting the treatment options for Acinetobacter intracranial infection; therefore, the use of only intravenous (IV) anti-infection drugs cannot effectively treat intracranial infection. Recent research has combined IV drug use and intraventricular (IVT) medication management to enhance drug concentrations at the site of infection $[11,12]$. Currently, the IVT administration of drugs for gram-negative bacterial meningitis includes aminoglycosides, colistin and polymyxin $\mathrm{B}$. According to recent reports on the treatment of central nervous system (CNS) infection, the effective treatment for multidrug-resistant (MDR) or extensively drugresistant (XDR) A. baumannii infection is the combination of IV and IVT drugs, and the drugs used for this treatment are mainly polymyxin $\mathrm{B}$ and tigecycline $[11,13$, 14]. However, the relevant reports are all studies with small sample sizes or are case reports. We report a case of severe craniocerebral trauma complicated by intracranial infection of XDR A. baumannii in the intensive care unit. The treatment process of sequential intrathecal injection of tigecycline and polymyxin B was successful, and the experience is shared in this report.

\section{Case presentation}

The patient, a 33-year-old male, was treated with intracranial hematoma clearance and bone flap decompression due to severe craniocerebral trauma caused by a high fall four months earlier. Twenty days after the surgery, consciousness disturbance was aggravated. Head computed tomography (CT) examination indicated increased hydrocephalus and CSF leakage, and ventricular borehole drainage and lumbar cistern drainage were performed several times (June 12, 2018). The CSF leukocyte count increased to $4000.0 \times 10^{6} / \mathrm{L}$ (Table 1). Staphylococcus aureus was found in the CSF culture, and the infection was treated with meropenem + vancomycin IV combined with vancomycin IVT. By July 2, 2018, the white blood cell count was reduced to $1.9 \times 10^{6} / \mathrm{L}$, blood glucose was 3.4 $\mathrm{mmol} / \mathrm{L}$, and protein was $0.30 \mathrm{~g} / \mathrm{L}$. Brain CT and magnetic resonance imaging (MRI) reexamination still indicated
Table 1 Laboratory examination of cerebrospinal fluid in patient with intracranial A. baumanni infection

\begin{tabular}{llll}
\hline Time point & WBC $\left(\times 10^{6} / \mathrm{L}\right)$ & Glu $(\mathrm{mmol} / \mathrm{L})$ & Protein $(\mathrm{g} / \mathrm{L})$ \\
\hline June 12, 2018 & 4000.0 & - & - \\
July 2, 2018 & 1.9 & 3.4 & 0.30 \\
July 8, 2018 & $29,887.0$ & 0.1 & 0.95 \\
July 12, 2018 & 848.0 & 2.0 & 1.73 \\
July 14, 2018 & 790.0 & 2.7 & 2.11 \\
July 15, 2018 & 743.0 & 2.7 & 1.77 \\
July 18, 2018 & 893.0 & 1.5 & 1.65 \\
July 21, 2018 & 144.0 & 2.2 & 1.56 \\
July 26, 2018 & 108.0 & 3.2 & 2.59 \\
July 31, 2018 & 121.0 & 3.2 & 1.63 \\
August 2, 2018 & 31.2 & 3.1 & 2.24 \\
\hline
\end{tabular}

severe hydrocephalus (Fig. 2a and b, Fig. 3a and b), and lumbar cistern drainage was performed again (July 8, 2018). The patients' bone window pressure at night increased significantly; the CSF exhibited a deep yellow color with turbidity and flocculation (Fig. 1a); and the patient had a high fever, with the highest temperature being $39.5^{\circ} \mathrm{C}$. The CSF white blood cell count was 29, $887.0 \times 10^{6} / \mathrm{L}$, the red blood cell count was $127 \times 10^{6} / \mathrm{L}$, blood glucose was $0.1 \mathrm{mmol} / \mathrm{L}$, protein was $0.95 \mathrm{~g} / \mathrm{L}$, and CSF cultures indicated XDR A. baumannii (Table 2). Left ventricular borehole drainage was performed (with holes closed for $1 \mathrm{~h}$ before opening), and the antibiotics were adjusted to meropenem $2 \mathrm{~g} \times \mathrm{q} 8 \mathrm{~h}+$ vancomycin $1 \mathrm{~g} \times \mathrm{q} 12$ $\mathrm{h}+$ tigecycline $100 \mathrm{mg} \times \mathrm{q} 12 \mathrm{~h}$ IV and tigecycline $5 \mathrm{mg} \times$ q12 h IVT. During the 7 days of the use of this regimen, the color of the CSF of the patient gradually faded, and the white blood cells decreased to $790 \times 10^{6} / \mathrm{L}$; the blood glucose was $2.7 \mathrm{mmol} / \mathrm{L}$, and the protein was $2.11 \mathrm{~g} / \mathrm{L}$ (July 15 , 2018). The white blood cell count in the CSF was $743 \times$ $10^{6} / \mathrm{L}$. CSF culture indicated that XDR A. baumannii was still present, and the indicators of liver function detected were higher than before. Suspected hepatic damage due to tigecycline was not excluded; therefore, we adjusted the antibiotic to be polymyxin B $100 \mathrm{mg} \times \mathrm{q} 12 \mathrm{~h}+$ meropenem $2 \mathrm{~g} \times \mathrm{q} 8 \mathrm{~h}+$ vancomycin $1 \mathrm{~g} \times \mathrm{q} 12 \mathrm{~h}$ IV anti-infection treatment and gave polymyxin $\mathrm{B} 10 \mathrm{mg} \times \mathrm{qd}$, which was changed to qod $\times 2 \mathrm{w}$ IVT 4 days later. The patient did not have fever after treatment, and the Glasgow Coma Scale (GCS) score increased from E1VTM1 to E1VTM5, which indicated that the patient's conscious state had improved. Head CT and MRI showed that the effusion was better than the previous absorption (Fig. 2c, d, e, and f, Fig. 3c and d, August 2, 2018). After reexamination, white blood cells in CSF gradually decreased to $31.2 \times 10^{6} / \mathrm{L}$, blood glucose was $3.1 \mathrm{mmol} / \mathrm{L}$, and protein was $2.24 \mathrm{~g} / \mathrm{L}$. Bacteria were not found in 4 CSF cultures, and the color of the CSF became pale yellow and transparent without flocculation (Fig. 1b, 

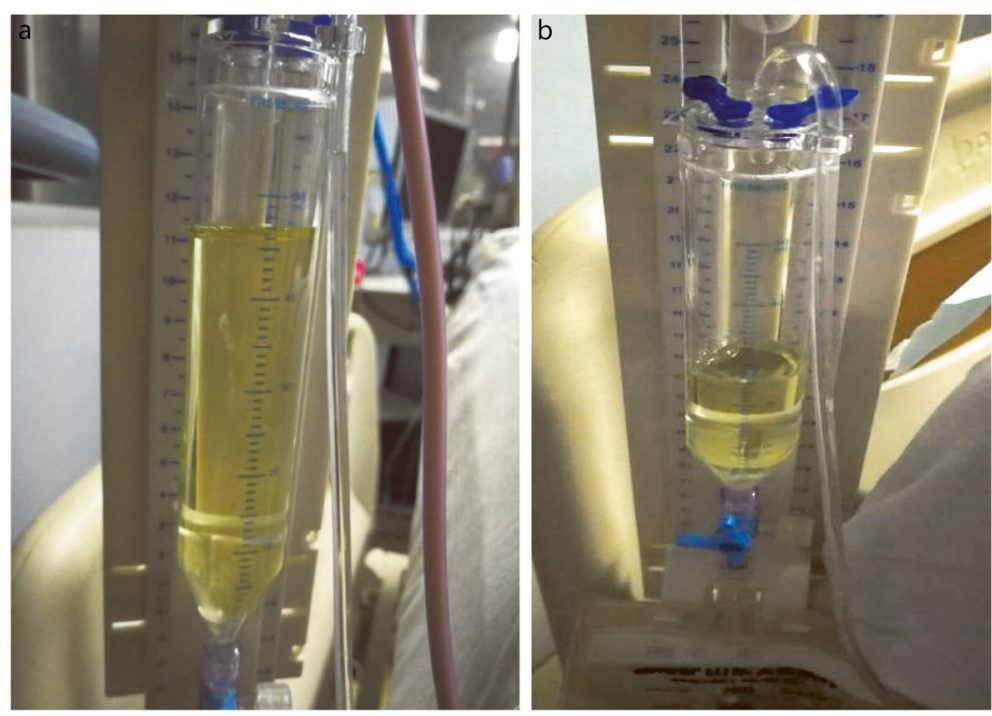

Fig. 1 Changes in cerebrospinal fluid (CSF) in patient with intracranial A. baumanni infection before and after treatment. a: CSF on July 8; b: CSF on August 2

August 3, 2018). The antibiotic was adjusted to ceftazidime $2 \mathrm{~g} \times \mathrm{q} 8 \mathrm{~h}+$ polymyxin B $100 \mathrm{mg} \times \mathrm{q} 12 \mathrm{~h}$ IV treatment. After further stabilization, the patient was transferred to the hospital for further brain rehabilitation.

\section{Discussion}

This paper discusses the anti-infection treatment strategy for a case of intracranial infection with XDR A. baumannii and describes the effects of tigecycline in its treatment.

\section{Anti-infection treatment strategy of intracranial infection with XDR A. baumannii}

According to previous reports, the main pathogens of surgical-site infection are gram-positive bacteria, especially

Table 2 Bacterial culture of CSF in patient with intracranial infection

\begin{tabular}{lll}
\hline Antibiotics & MIC & Drug sensitivity \\
\hline Piperacillin and tazobactam & 128 & $\mathrm{R}$ \\
Ceftazidime & 64 & $\mathrm{R}$ \\
Cefoperazone/Sulbactam & 64 & $\mathrm{R}$ \\
Cefepime & 32 & $\mathrm{R}$ \\
Imipenem & 16 & $\mathrm{R}$ \\
Meropenem & 16 & $\mathrm{R}$ \\
Tobramycin & 16 & $\mathrm{R}$ \\
Minocycline & 8 & $\mathrm{I}$ \\
$\quad$ Tigecycline & 1 & $\mathrm{~S}$ \\
Colistin & 0.5 & $\mathrm{~S}$ \\
Trimethoprim/Sulfamethoxazole & 20 & $\mathrm{~S}$ \\
\hline
\end{tabular}

MIC: Minimum inhibitory concentration; R: Resistant; I: Intermediate; S: Susceptible
Staphylococcus aureus [15]. In this case, Staphylococcus aureus was found in the CSF culture at the time of the first intracranial infection, which was consistent with the pathogen species mentioned in the report. Vancomycin IV and IVT are the main therapeutic drugs for the intracranial infection of gram-positive cocci [16]. However, in the closed environment of hospitals, the generation of drugresistant bacteria is becoming increasingly serious. In addition, neurosurgery, CSF leakage, long-term and repeated ventricular drainage, the use of broad-spectrum antibiotics, long-term mechanical ventilation and stay in the intensive care ward and intracranial hemorrhage are all high-risk factors for the generation of drug-resistant bacteria [17]. The average time to develop A. baumannii infection is 12 days (range 40 days) [17]. There have also been reports on the discovery of a previous pathogen, as well as the detection of a new pathogen, and the emergence of drug-resistant bacteria ranges from 3 to 90 days [18]. In this study, the time for the development of $A$. baumannii in CSF culture was 28 days. We know that polymyxin has been in use since the 1950s, but its use rate has decreased year by year due to severe nephrotoxicity and neurotoxicity. However, in recent years, researchers have found that polymyxin is active against both MDR and XDR gram-negative bacteria, including A. baumannii, and researchers have attempted to use the IVT pathway in patients with intracranial infection $[5,13,19]$. Colistin has CNS permeability. In recent years, colistin has been recommended in studies to treat intracranial infection caused by multidrug-resistant bacteria. The IVT and IV injection of colistin are currently also options for treatment, and some success has been achieved in the cases studied [5, 7]. In this report, $A$. baumannii was found in the CSF culture when the white blood cell counts in the CSF had become 

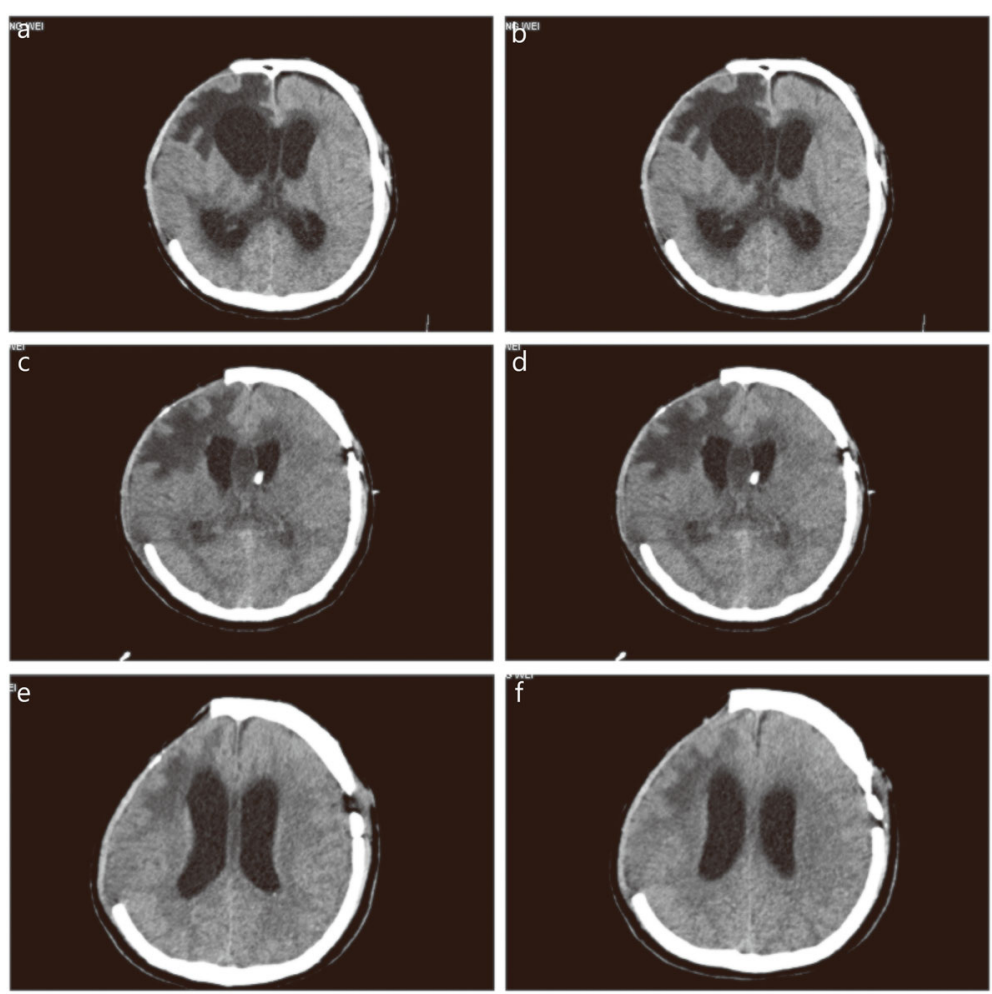

Fig. 2 Brain CT after admission in patient with intracranial A. baumanni infection. a. Before the treatment on July 3, large low-density shadows were seen in the right frontotemporal parietal lobe; b. Before the treatment on July 3, large low-density shadows appeared in the bilateral lateral ventricles and the third ventricle dilated; c. During the treatment on July 16 , bilateral lateral ventricle and the third ventricle were dilated, and hydrocephalus was better than before; $d$. During the treatment on July 16, a free tube shadow was seen through the left frontal bone to the anterior horn of the left ventricle; e. After treatment on August 2, the original free tube shadow was removed; f. After treatment on August 2, bilateral lateral ventricular hydrocephalus was observed

elevated again in the patient. The drug sensitivity results indicated that the patient was sensitive to polymyxin B. At that time, there was no polymyxin $B$ or polymyxin $E$ in the Chinese market. After the patient's wife purchased polymyxin B from Hong Kong, we gave the patient this drug. Therefore, polymyxin B IV and IVT schemes, namely, polymyxin B $100 \mathrm{mg} \times \mathrm{q} 12 \mathrm{~h} \mathrm{IV}$ and $10 \mathrm{mg} \times \mathrm{qd}$, were used and changed to qod $\times 2 \mathrm{w}$ IVT 4 days later. According to the guidelines issued by the American Academy of Infectious Diseases for the treatment of bacterial meningitis, the dose of ventricular colistin should be 10 mg per day [20] with satisfactory results. During this process, the renal function of the patient was closely monitored, and no nephrotoxicity or neurotoxic side effects were observed. For polymyxin B injection, based on the evidence provided and the IV and IVT joint scheme, colistin is an ideal drug because it has good antibacterial activity against MDR or XDR A. baumannii, but clinicians need to be mindful of mucin-related complications, including chemical meningitis inflammation, chemical
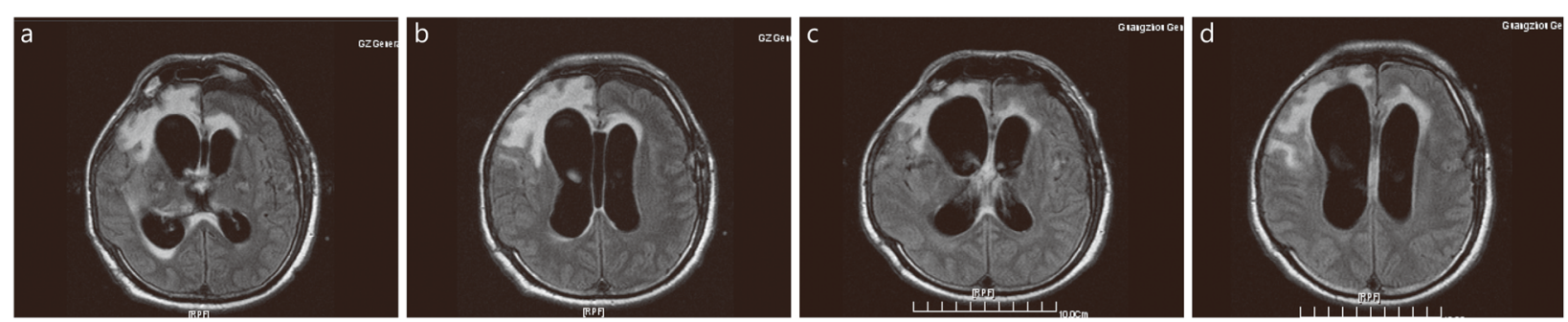

Fig. 3 Brain MRI in patient with intracranial A. baumanni infection before and after treatment. a.: On July 4, subarachnoid hemorrhage occurred in the right frontal lobe; b. On July 4, midline, subdural effusion and hydrocephalus occurred in the left frontal part; $c$. On July 24 , subarachnoid hemorrhage in the right frontal lobe; $d$. On July 24 , midline and subdural effusion in the left frontal part were better than before 
ventricle inflammation, seizures and horsetail nerve syndrome (there have been reported incidences of 21.7\%) [5]. Close monitoring of renal function during treatment, more careful management of fluids and electrolytes, and the avoidance of combination with other drugs known to be nephrotoxic may reduce the incidence of associated side effects.

\section{Characteristics of tigecycline in the treatment of intracranial XDR A. baumannii}

According to recent progress in the treatment of CNS infection, tigecycline is often the first clinical application. Because of the ammonia acyl ring element compounds of this drug, tigecycline has a wide variety of activities among MDR pathogens. Tigecycline usually displays good antibacterial activity against resistant gramnegative and gram-positive bacteria, as do many antimicrobial drugs according to synergy, but due to the lack of penetration to the CNS, their serum concentration in the CSF is only $11 \%[21,22]$. Therefore, the IV injection of tigecycline has no significant effect on patients with intracranial infection, and routine intravenous use of tigecycline is not recommended for $A$. baumannii meningitis. In recent years, there have been notably few reports of the successful IVT use of tigecycline $[14,23-25]$. In this report, when $A$. baumannii was found in the first culture, we used tigecycline $100 \mathrm{mg} \times$ $\mathrm{q} 12 \mathrm{~h}$ IV and $5 \mathrm{mg} \times \mathrm{q} 12 \mathrm{~h}$ IVT according to the drug sensitivity. During the 7 days of use, the number of white blood cells in the CSF repeatedly decreased, and the clinical symptoms of the patient were significantly improved without neurotoxic side effects. We have no pharmacokinetic data in our report because our hospital currently cannot monitor the concentrations of tigecycline or polymyxin B in serum and CSF. However, according to the literature, various dosages of tigecycline (49 mg intravenously and $1 \mathrm{mg}$ intraventricularly every $12 \mathrm{~h}, 45 \mathrm{mg}$ intravenously and $5 \mathrm{mg}$ intraventricularly every $12 \mathrm{~h}$, or $40 \mathrm{mg}$ intravenously and $10 \mathrm{mg}$ intraventricularly every $12 \mathrm{~h}$ ) are well tolerated and effective. After a dose of $5 \mathrm{mg}$ intraventricularly every $12 \mathrm{~h}$, CSF peak-trough concentrations were approximately (327.0$1.7 \mathrm{mg} / \mathrm{L}$ ). The dose of tigecycline we used was consistent with the reported dose in the literature; therefore, the corresponding pharmacokinetics should be consistent. Moreover, according to the guidelines issued by the American Academy of Infectious Diseases for the treatment of bacterial meningitis, the dose of ventricular colistin should be $10 \mathrm{mg} / \mathrm{d}$, but there is a lack of information on the pharmacokinetics of polymyxin B after administration to patients via routes other than IV injection (e.g., inhalation, intrathecal injection, and IVT injection). The literature reported similar antibacterial activity in vitro, and two studies have reported the pharmacokinetics (PK) results of colistin after intrathecal administration (ITH)/ IVT colistin methanesulfonate (CMS) application in patients. In one of the studies, when patients were treated with CMS $5.22 \mathrm{mg} / \mathrm{d}$, the CSF concentrations of colistin were continuously above $2 \mu \mathrm{g} / \mathrm{ml}$, and the $\mathrm{C}_{\max } / \mathrm{MIC}$ ratio was $\geq 3.5$.

\section{Conclusion}

IVT tigecycline injection seems to be a safe treatment for A. baumannii intracranial infection. Unfortunately, we did not measure tigecycline concentration in CSF. Currently, there are no large-sample clinical RCT studies, and only scarce reports have been presented, but the effectiveness of the IVT injection of tigecycline still needs to be further studied.

\section{Abbreviations}

CNS: Central nervous system; CSF: Cerebrospinal fluid; CT: Computed tomography; GCS: Glasgow Coma Scale; IV: Intravenous; IVT: Intraventricular; ITH: Intrathecal administration; MIC: Minimum inhibitory concentration; MRI: Magnetic resonance imaging; MDR: Mulitidrug-resistant; PK: Pharmacokinetics; XDR: Extensively drug-resistance

\section{Acknowledgements}

Not applicable.

\section{Authors' contributions}

ZFL, LZ, XZS and LS participated in the treatment of this patient and were involved in the development of the conclusions. LZ wrote the first draft with assistance from ZFL, XZS and LS edited the final draft. All authors had read and approved the final manuscript.

\section{Funding}

This work was supported by grants from the National Natural Science Foundation of China (81571940; 81741125), the Guangzhou Science and Technology Planning Project of China (201504281714528), PLA Logistics Research Project of China (CWH17L020, 17CXZ008, 18CXZ030).

Availability of data and materials

Not applicable.

Ethics approval and consent to participate

Not applicable.

\section{Consent for publication}

Written informed consent for publication of the clinical details and clinical images was obtained from the patient.

\section{Competing interests}

The authors declare that they have no competing interests.

\section{Author details}

'Second Clinical College of Guangzhou University of Chinese Medicine, Guangzhou 510515, China. ${ }^{2}$ Department of Critical Care Medicine, the First Affiliated Hospital of Guizhou University of Chinese Medicine, Guiyang 550001, China. ${ }^{3}$ Department of Critical Care Medicine, General Hospital of Southern Theater Command of PLA, Guangzhou 510010, China. ${ }^{4}$ Key Laboratory of Hot Zone Trauma Care and Tissue Repair of PLA, General Hospital of Southern Theater Command of PLA, Guangzhou 510010, China.

Received: 12 October 2019 Accepted: 3 May 2020

Published online: 10 May 2020

References

1. Fang C, Zhu T, Zhang P, Xia L, Sun CX. Risk factors of neurosurgical site infection after craniotomy: a systematic review and meta-analysis. Am J Infect Control. 2017;45(11):e123-4. 
2. McClelland S 3rd, Hall WA. Postoperative central nervous system infection: incidence and associated factors in 2111 neurosurgical procedures. Clin Infect Dis. 2007:45(1):55-9.

3. Korinek AM, Baugnon T, Golmard JL, van Effenterre R, Coriat P, Puybasset L. Risk factors for adult nosocomial meningitis after craniotomy: role of antibiotic prophylaxis. Neurosurgery. 2008;62(Suppl 2):532-9.

4. Thigpen MC, Whitney CG, Messonnier NE, Zell ER, Lynfield R, Hadler JL, et al. Bacterial meningitis in the United States, 1998-2007. N Engl J Med. 2011; 364(21):2016-25

5. Karaiskos I, Galani L, Baziaka F, Giamarellou H. Intraventricular and intrathecal colistin as the last therapeutic resort for the treatment of multidrug-resistant and extensively drug-resistant Acinetobacter baumannii ventriculitis and meningitis: a literature review. Int J Antimicrob Agents. 2013;41(6):499-508.

6. Kurtaran B, Kuscu F, Ulu A, Inal AS, Komur S, Kibar F, et al. The causes of postoperative meningitis: the comparison of gram-negative and grampositive pathogens. Turk Neurosurg. 2018;28(4):589-96.

7. Kim HI, Kim SW, Park GY, Kwon EG, Kim HH, Jeong JY, et al. The causes and treatment outcomes of 91 patients with adult nosocomial meningitis. Korean J Intern Med. 2012;27(2):171-9.

8. Huttova M, Freybergh PF, Rudinsky B, Sramka M, Kisac P, Bauer F, et al. Postsurgical meningitis caused by Acinetobacter baumannii associated with high mortality. Neuro Endocrinol Lett. 2007;28(Suppl 2):15-6.

9. Metan G, Alp E, Aygen B, Sumerkan B. Acinetobacter baumannii meningitis in post-neurosurgical patients: clinical outcome and impact of carbapenem resistance. J Antimicrob Chemother. 2007;60(1):197-9.

10. Karageorgopoulos DE, Falagas ME. Current control and treatment of multidrug-resistant Acinetobacter baumannii infections. Lancet Infect Dis. 2008;8(12):751-62.

11. Nau R, Seele J, Djukic M, Eiffert H. Pharmacokinetics and pharmacodynamics of antibiotics in central nervous system infections. Curr Opin Infect Dis. 2018;31(1):57-68.

12. Nau R, Sorgel F, Eiffert $H$. Penetration of drugs through the bloodcerebrospinal fluid/blood-brain barrier for treatment of central nervous system infections. Clin Microbiol Rev. 2010;23(4):858-83.

13. De Bonis P, Lofrese G, Scoppettuolo G, Spanu T, Cultrera R, Labonia M, et al. Intraventricular versus intravenous colistin for the treatment of extensively drug resistant Acinetobacter baumannii meningitis. Eur J Neurol. 2016;23(1): 68-75.

14. Wu Y, Chen K, Zhao J, Wang Q, Zhou J. Intraventricular administration of tigecycline for the treatment of multidrug-resistant bacterial meningitis after craniotomy: a case report. J Chemother. 2018;30(1):49-52.

15. Chen K, Wu Y, Wang Q, Wang J, Li X, Zhao Z, et al. The methodology and pharmacokinetics study of intraventricular administration of vancomycin in patients with intracranial infections after craniotomy. J Crit Care, 2015, 30(1): 218.e211-5.

16. Wu Y, Kang J, Wang Q. Drug concentrations in the serum and cerebrospinal fluid of patients treated with norvancomycin after craniotomy. Eur J Clin Microbiol Infect Dis. 2017;36(2):305-11.

17. Kim BN, Peleg AY, Lodise TP, Lipman J, Li J, Nation R, et al. Management of meningitis due to antibiotic-resistant Acinetobacter species. Lancet Infect Dis. 2009;9(4):245-55.

18. Huang CR, Chen SF, Lu CH, Chuang YC, Tsai NW, Chang CC, et al. Clinical characteristics and therapeutic outcomes of nosocomial super-infection in adult bacterial meningitis. BMC Infect Dis. 2011;11:133.

19. De Pascale G, Pompucci A, Maviglia R, Spanu T, Bello G, Mangiola A, et al. Successful treatment of multidrug-resistant Acinetobacter baumannii ventriculitis with intrathecal and intravenous colistin. Minerva Anestesiol. 2010;76(11):957-60.

20. Tunkel AR, Hasbun R, Bhimraj A, Byers K, Kaplan SL, Scheld WM, et al. 2017 Infectious Diseases Society of America's clinical practice guidelines for healthcare-associated ventriculitis and meningitis. Clin Infect Dis. 2017;64(6): e34-65.

21. Rodvold KA, Gotfried MH, Cwik M, Korth-Bradley J, Dukart G, Ellis-Grosse EJ. Serum, tissue and body fluid concentrations of tigecycline after a single 100 mg dose. J Antimicrob Chemother. 2006;58(6):1221-9.

22. Ray L, Levasseur K, Nicolau DP, Scheetz MH. Cerebral spinal fluid penetration of tigecycline in a patient with Acinetobacter baumannii cerebritis. Ann Pharmacother. 2010;44(3):582-6.

23. Tutuncu EE, Kuscu F, Gurbuz Y, Ozturk B, Haykir A, Sencan I. Tigecycline use in two cases with multidrug-resistant Acinetobacter baumannii meningitis. Int J Infect Dis. 2010;14(Suppl 3):e224-6.
24. Lauretti L, D'Alessandris QG, Fantoni M, D'Inzeo T, Fernandez E, Pallini R, et al. First reported case of intraventricular tigecycline for meningitis from extremely drug-resistant Acinetobacter baumannii. J Neurosurg. 2017;127(2): 370-3.

25. Fang $Y Q$, Zhan $R C$, Jia W, Zhang BQ, Wang JJ. A case report of intraventricular tigecycline therapy for intracranial infection with extremely drug resistant Acinetobacter baumannii. Medicine (Baltimore). 2017;96(31): e7703.
Ready to submit your research? Choose BMC and benefit from:

- fast, convenient online submission

- thorough peer review by experienced researchers in your field

- rapid publication on acceptance

- support for research data, including large and complex data types

- gold Open Access which fosters wider collaboration and increased citations

- maximum visibility for your research: over $100 \mathrm{M}$ website views per year

At $\mathrm{BMC}$, research is always in progress.

Learn more biomedcentral.com/submissions 